\title{
RADIOMETRIC CHARACTERIZATION OF A MARSH SITE AT THE ARGENTINIAN PAMPAS IN THE CONTEXT OF HYPERNETS PROJECT (A NEW AUTONOMOUS HYPERSPECTRAL RADIOMETER)
}

\author{
E. Piegari ${ }^{1}$, J. I. Gossn ${ }^{1}$, Á. Juárez ${ }^{2}$, V. Barraza ${ }^{1}$, G. González Trilla ${ }^{3}$, F. Grings ${ }^{1 *}$ \\ ${ }^{1}$ Instituto de Astronomía y Física del Espacio (IAFE), CONICET-UBA \\ ${ }^{2}$ Dto. Biodiversidad y Biología Experimental. FCEyN-UBA \\ ${ }^{3}$ Instituto de Investigación e Ingeniería Ambiental (3ia), CONICET-UNSAM
}

Commission

\begin{abstract}
:
In the context of HYPERNETS project, which is developing a relatively low cost hyperspectral radiometer (and associated pointing system and embedded calibration device for automated measurement of water and land bidirectional reflectance), the tidal coastal marsh in the Mar Chiquita (Argentina) lagoon is being characterized as a test site for validation of radiometric variables. High quality in situ measurements will be available at all spectral bands at this site (and other sites over land and water around the world) for the validation of the surface reflectance data issued from all earth observation missions. This site, dominanted by Sporobolus densiflorus vegetation, is a coastal habitat that provides ecosystem services essential to people and the environment. There is evidence that growth and photosynthetic apparatus of $S$. densiflorus is negatively affected by the herbicide glyphosate, which is extensively used in the Argentinian agricultural production. As a way to monitor this risk, in this work a theoretical study was performed to establish if it is possible to estimate the chlorophyll content $\left(C_{a+b}\right.$ in $S$. densiflorus $)$, which concentrations are known to be affected by the herbicide, using hyperspectral reflectance. Signatures recorded in situ plus other parameters obtained from a biochemical characterization of the plant were used to obtain a simulated reflectance with the radiative transfer model PROSAIL. Then, a BaseLine Residual approach, based on close band triplets, was proposed to retrieve $C_{a+b}$. As a result, we found that it is possible to distinguish between two levels of $C_{a+b}$.
\end{abstract}

\section{INTRODUCTION}

In order to produce research-quality data from existing and future satellite observing systems, it is essential to perform extensive validation campaigns or to set up test sites for validation of radiometric variables. This is necessary to: (1) characterize surface biophysical dynamics to develop appropriate retrieval algorithms and (2) for quality control of geophysical data derived from remote sensing data. Moreover, in the context of HYPERNETS project, which is developing a relatively low cost hyperspectral radiometer (and associated pointing system and embedded calibration device for automated measurement of water and land bidirectional reflectance), the availability of robust and well characterized field validation sites is critical.

In particular, monitoring salt marsh ecosystems is essential since they provide important services to the environment, such as the protection of the coastline and the improvement of estuarine water quality, and are highly valued for the benefits that contribute to society (Ecosystem Milenium 2005). Wetlands are very sensitive to changes in environmental conditions and, consequently, are a good indicator of early signs of any physical or chemical degradation (Bedford, Preston, 1988).

In the present study a marsh site (Mar Chiquita coastal lagoon) is characterized in terms of its spectral variability based on radiometric in situ data. The dominant vegetation in this site is Sporobolus densiflorus, which is native in Argentina but it is considered invasive in the U.S. and Europe. As a way to control the invasion in Spain a work by Mateos-Naranjo examined the effect of different doses of glyphosate on growth and photosynthetic apparatus of S. densiflorus (Mateos-Naranjo et al., 2009).

\footnotetext{
*Corresponding author
}

Many effects were observed but in particular it was shown that photosynthetic pigments such as chlorophyll a, chlorophyll b and carotenoids decrease with glyphosate concentration after 30 days of treatment.

Given the importance of this ecosystem, our objective in this study was to develop an strategy to monitor biophysical variables using hyperspectral data on the tidal coastal marsh in the Mar Chiquita (Argentina) lagoon. Leaf pigment content can provide valuable information concerning the physiological state of leaves. Measurement of spectral reflectance provides a fast, non destructive method for pigment estimation. In particular, chlorophyll tends to decline more rapidly than carotenoids when plants are under stress or during leaf senescence (Sims, Gamon, 2002, Gitelson, Merzlyak, 1994a, Gitelson, Merzlyak, 1994b). Several techniques have been proposed to estimate the chlorophyll content $\left(C_{a+b}\right)$, like radiative transfer model inversion or semi-empirical relationships with vegetation indices (Zarco-Tejada et al., 2019). In particular, from an application point of view, $C_{a+b}$ is of interest because it has been shown that it is negatively affected by the herbicide glyphosate, which is extensevely used in the Argentinian agricultural production.

To distinguish reflectance changes in the region that varies with $C_{a+b}$ it is necessary to measure the reflectances of narrow bands. Hyperspectral sensors provide detailed spectral information and offer the potential to detect and map changes subtle in the vegetation of the wetlands (Hestir et al., 2008, Vaiphasa et al., 2007, Schmidt, Skidmore, 2003) and (Clevers, Kooistra, 2012) showed that hyperspectral data might provide addtional information at the red-edge region to estimate $C_{a+b}$.

In this work, we performed a theoretical study to establish if it is 
possible to estimate $C_{a+b}$ in Sporobolus densiflorus with hyperspectral reflectances. The methodology presented here consist in using measured reflectances to reproduce the spectral signature of $S$. densiflorus using the PROSAIL radiative transfer model. Here, a BaseLine Residual model is proposed to retrieve $C_{a+b}$ in the plant. As a result, an indicator of $C_{a+b}$ changes is obtained where two conditions can be distinguished, a low or a normal value of $C_{a+b}$.

\section{DATA AND METHODS}

\subsection{Study area}

The Mar Chiquita coastal lagoon is on the coast of the Buenos Aires Province, Argentina, $\left(37^{\circ} 32^{\prime}\right.$ to $37^{\circ} 45^{\prime} \mathrm{S}$ and $57^{\circ} 19^{\prime}$ to $57^{\circ} 26^{\prime} \mathrm{W}$, Fig. 1A). It is located in a temperate zone. The Mar Chiquita lagoon is a brackish waterbody that covers about 60 $\mathrm{km}^{2}$, with a drainage basin of about $10000 \mathrm{~km}^{2}$ and affected by $1 \mathrm{~m}$ amplitude tides (Marcovecchio et al., 2006). The lagoon is separated from the sea by a barrier dune over $40 \mathrm{~km}$ long and connects to the ocean through a single tidal channel.

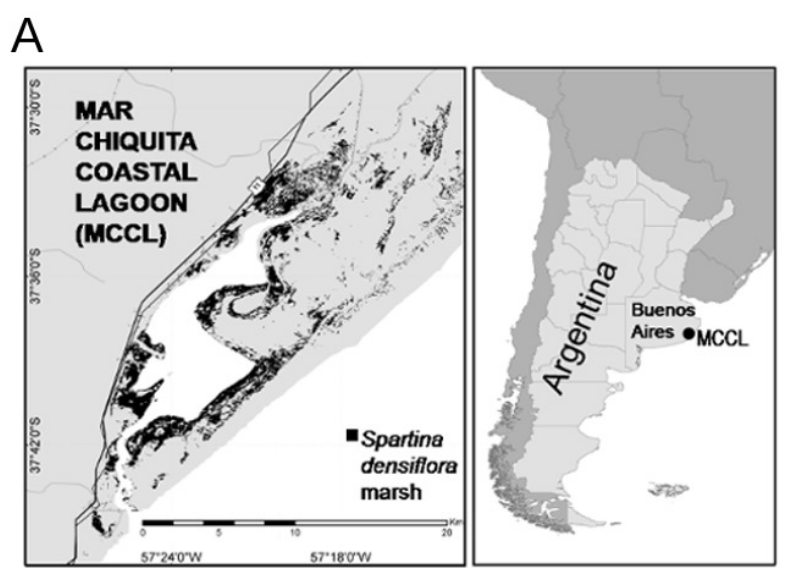

B

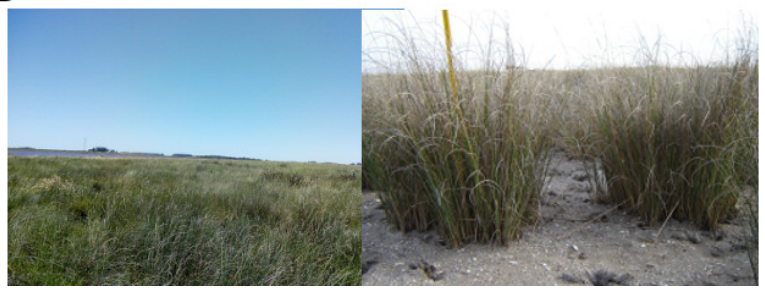

Figure 1. Location of the site of study (A) and pictures of the dominant vegetation Sporobolus densiflorus (B).

The dominant vegetation is Sporobolus densiflorus (Fig. 1B), a perennial grass that forms dense clumps and exhibits $\mathrm{C} 4$ photosynthetic metabolism, as all species of this genus. It presents a wide range of environmental tolerance, and can be found from brackish to hypersaline conditions, and intertidal to strictly terrestrial habitats (Vicari et al., 2002). This species is characterized by a caespitose growth form, expanding vegetatively by short tillers or sexually via high seed production (Bortolus, 2006). Sporobolus densiflorus populations are found in middle and upper intertidal zones, including ecotones with adjacent terrestrial ecosystems (Castillo et al., 2000). This distribution pattern is observed both in the Buenos Aires province where this species is native (Bortolus, 2006, González Trilla et al., 2010) and in the U.S. and Europe where it is invasive (Castillo et al.,
2000, Nieva et al., 2001). For more detail see (González Trilla et al., 2013).

\subsection{Spectral sampling and LAI acquisition}

Spectral signatures at high resolution were measured in $S$. densiflorus canopies under natural conditions, manipulating standing crop by means of successive harvest, to reproduce the wide biomass and percentage of coverage interplant variation. Reflectance data were acquired using a field spectrometer (FieldSpec $囚$ Analytical Spectral Devices, Inc.), which covers the regions of the spectrum between 350 and $2500 \mathrm{~nm}$, with a bandwidth of $1 \mathrm{~nm}$. Regions between 1344 and 1446 $\mathrm{nm}$ and between 1799 and 1996 were removed due to noise related to atmosphere absorption in those ranges (for more detail see (González Trilla et al., 2013)). For each signature the Leaf Area Index (LAI) was measured as explained in (González Trilla et al., 2013).

\subsection{Biochemical features of Sporobolus densiflorus}

We characterized some biochemical features $\left(C_{a+b}, C_{a r}\right.$, $E W T$ and $D M C$ ) of $S$. densiflorus in order to determine the range of some of the parameters in the model. To this end, during a campaign performed in December 2018 we took samples and then analyzed them at the laboratory. To determine the photosyntetic pigments content range, 27 leaves of 3 tillers in 3 plants, entire leaves were ground, extracted in $3 \mathrm{ml} \mathrm{100 \%} \mathrm{meth-}$ anol and centrifuged to remove particulates. The absorbance of the extract solutions was measured with the Pg Instruments Ltd T80 UV/VIS spectrometer to acquire the absorption measurements necessary to calculate the total chlorophyll and the carotenoid concentrations $\left(C h l_{a+b}\right.$ and $C_{x+c}$ in (Lichtenthaler, Buschmann, 2001)). To obtain chlorophyll $\mathrm{a}+\mathrm{b}$ and carotenoid contents in micrograms per unit of leaf area $\left(C_{a+b}\right.$ and $C_{a r}$, respectively), a linear regression was used to calculate the leaf area by measuring the longitude of each leaf (Trilla et al., 2013).

Measuring the fresh weight and the dry weight of four crops, the range of Equivalent Water Thickness $(E W T)$ and the Dry Matter content $(D M C)$ were estimated for $S$. densiflorus.

\subsection{The PROSAIL radiative transfer model}

Simulated signatures of Sporobolus densiflorus were obtained using the PROSAIL radiative transfer model that combines the PROSPECT (Jacquemoud, Baret, 1990) and the SAIL models (Verhoef, 1985). The coupling of these two models simply consists in passing the output leaf reflectance and transmittance of the PROSPECT model into the SAIL model to simulate the whole canopy bidirectional reflectance at given solar and viewing angles (Jacquemoud et al., 2009).

The PROSPECT model uses two classes of input variables: the parameters related to leaf biochemistry (the chlorophyll content $C_{a+b}$, the carotenoid content $C_{c a r}$, the brown pigment content $C_{b p}$, the equivalent water thickness $E W T$ and the dry matter content $D M C$ ) and the leaf structure parameter $\mathrm{N}$, which is the number of compact layers specifying the average number of air/soil walls interfaces within the mesophyll. In the SAIL Model, the parameters that take into account the canopy architecture are the leaf area index $(L A I)$, hot-spot parameter $\left(h_{\text {spot }}\right)$ and the mean leaf inclination angle $\left(\theta_{\text {leaf }}\right)$. Additionally, there are other parameters in the SAIL model such as the ratio of diffuse to total incident radiation $(s k y l)$, the soil reflectance 
$\left(\rho_{\text {soil }}\right)$, the sun zenith angle $(t t s)$, the viewing zenith angle $(t t o)$ and the relative zenith angle (psi).

Input parameters were determined based on the range measured in the laboratory and field (shown in Secs. 2.3 and 2.2) and from PROSAIL applications for grassland vegetations (Si et al., 2012, Quan et al., 2017). The solar zenith angle, viewing zenith angle and relative azimuth angle were left fixed and the mean measured soil reflectances was given as an input. The value or range of the parameters used are listed in Table 1.

\begin{tabular}{|cccc|}
\hline Model & Parameter & Units & Value \\
\hline PROSPECT & $C_{a+b}$ & $\mu \mathrm{g} / \mathrm{cm}^{2}$ & $0-6$ \\
& $C_{c a r}$ & $\mu \mathrm{g} / \mathrm{cm}^{2}$ & $0-3$ \\
& $C_{b p}$ & $\mu \mathrm{g} / \mathrm{cm}^{2}$ & $0-4$ \\
& $D M C$ & $\mathrm{~g} / \mathrm{cm}^{2}$ & $0.0001-0.03$ \\
& $E W T$ & $\mathrm{~cm}$ & $0.0001-0.03$ \\
SAIL & $N$ & - & $1-2$ \\
& $L A I$ & - & 45 \\
& $h_{\text {spot }}$ & - & $0.0001-0.2$ \\
& $\theta_{\text {leaf }}$ & deg & $70-90$ \\
& skyl & - & - \\
& tts & deg & 30 \\
& tto & deg & 0 \\
& psi & deg & 0 \\
\hline
\end{tabular}

Table 1. Value or range of input parameters used in the PROSAIL model.

The methodology used to obtain the PROSAIL model parameters that best fit the experimental reflectances is an iterative numerical minimization of the distance, $\delta$, between the measured and the simulated spectral signature $\left(\rho_{\text {exp }}\right.$ and $\rho_{\text {sim }}$, respectively, weighted to fit the red edge region (Eq. 1). This is:

$$
\delta=\sum_{\lambda_{i}}\left(\rho_{\text {exp }}-\rho_{\text {sim }}\right) \cdot W\left(\lambda_{i}\right)
$$

with $W=100$ between $(400-650) n m, W=20000$ between $(650-750) \mathrm{nm}, W=10$ between $(750-1300) \mathrm{nm}$ and $W=1$ in the rest.

\subsection{BLR approach for $C_{a+b}$ estimation}

Instead of using indices to retrieve $C_{a+b}$, we proposed to compute the Baseline Residual as previously shown in (Gossn et al., 2019). The BLR calculates the difference between the middle (M) band signal and the value of the baseline formed by the signals at the left (L) and right (R) bands at this middle wavelength (Eq. 2).

$$
B L R\left(\lambda_{L}, \lambda_{M}, \lambda_{R}\right)=\rho_{R C}\left(\lambda_{M}\right)-B L\left(\lambda_{M} \mid \lambda_{L}, \lambda_{R}\right)
$$

where $\rho$ is the reflectance and $B L\left(\lambda_{M} \mid \lambda_{L}, \lambda_{R}\right)=$ $\frac{\rho\left(\lambda_{L}\right)\left(\lambda_{R}-\lambda_{M}\right)+\rho\left(\lambda_{R}\right)\left(\lambda_{M}-\lambda_{L}\right)}{\lambda_{R}-\lambda_{L}}$ is the value reached at $\lambda_{M}$ by the baseline formed by the left and right bands.

A BaseLine Residual modeled grid was constructed varying $C_{a+b}$ and LAI while maintaining the other parameters of the model, fixed. Two BLRs grids are computed using the reflectance of three bands in two regions: one $\left(\mathrm{BLR}_{2}\right)$ that only varies with $\mathrm{LAI}$, and the second $\left(\mathrm{BLR}_{1}\right)$ that presents variations with $C_{a+b}$ and with LAI. In particular, the 6 bands selected were: $657,672,700,800,1100$ and $1300 \mathrm{~nm}$.

In this way, the complete signature can be reduced to two BLRs defined by two triplet bands. The advantage of using the BLR approach is that the reflectance of the triplet's middle band after baseline subtraction is quasi invariant under different atmospheric conditions.

\section{RESULTS}

\subsection{PROSAIL simulations}

We took $S$, densiflorus signatures recorded with a field radiometer in Mar Chiquita corresponding to different vegetation cover. In Fig. 2 two reflectances examples that indicate the great reflectance variation among plants are shown.
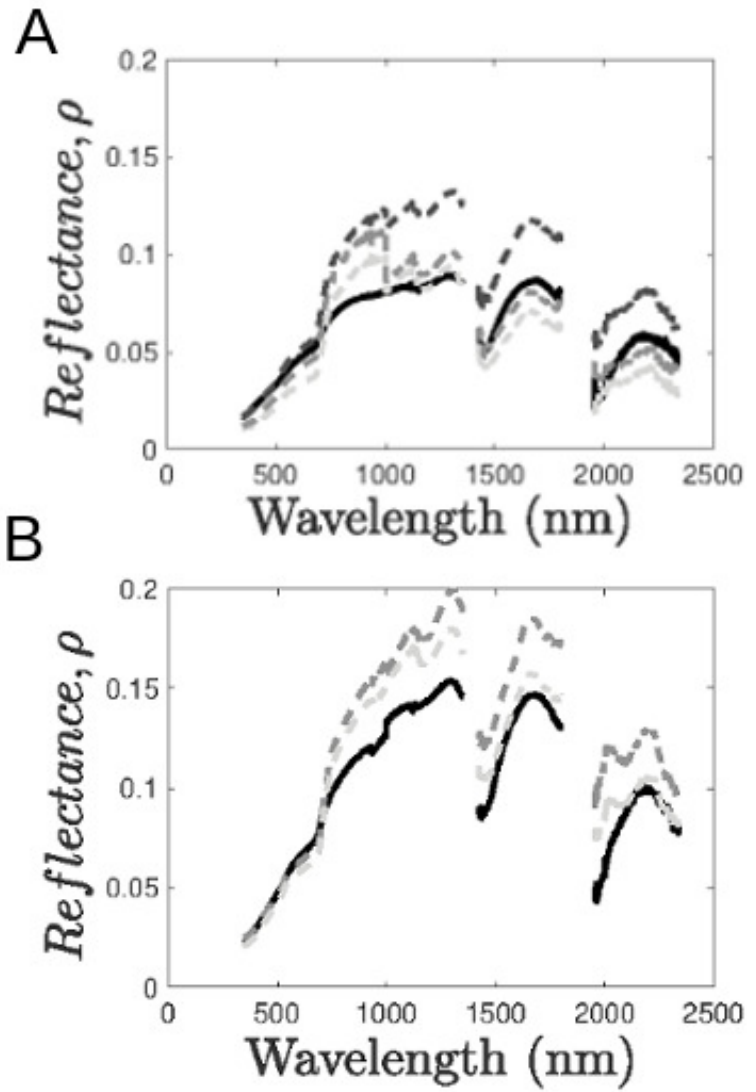

Figure 2. S. densiflorus signatures recorded with a field radiometer. Variability in the reflectances of this vegetation is shown in two examples (A-B) In each figure reflectance measurements taken after each successive harvest are plotted in dotted lines, as explained in Sec.2.2. The bare soil is plotted in solid black line.

Various reflectance measurements represented by dotted lines are plotted in each figure. These were taken after each successive harvest, performed to vary the vegetation cover, avoiding the effects of changing soil conditions. The final measurement of the bare soil is represented by the solid black line.

Applying the method explained in Sec. 2.4, given the soil reflectance as an input (the mean of the measured soils), we obtained simulated signatures that fit the in situ reflectances of $S$. densiflorus. One example can be observed in Fig. 3, where measured reflectances $\left(\rho_{\text {exp }}\right)$ are plotted in red and simulated reflectances $\left(\rho_{\text {sim }}\right)$ in black. The root mean square error (RMSE) is 0.016 . 


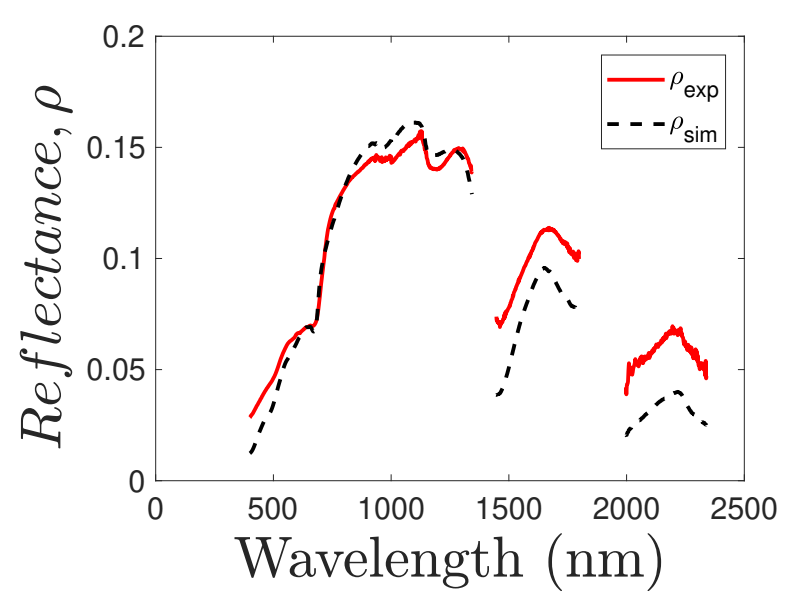

Figure 3. Example of simulated signatures of $S$. densiflorus reflectances obtained using the PROSAIL model and an iterative minimization method performed as explained in Sec. 2.4. $\rho_{\text {exp }}$ is plotted in red and $\rho_{\text {sim }}$ in black

The simulated LAI values correlate with the measured value in each signature (coefficient of correlation $r=0.82$ ). The parameter distributions obtained from the simulated reflectances are shown in Fig. 4.

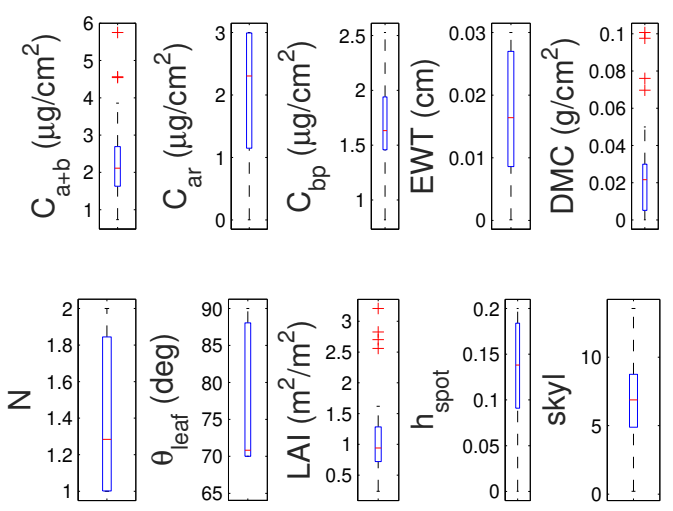

Figure 4. Parameter distribution obtained from the simulated reflectances of $S$. densiflorus.

\subsection{Sensitivity analysis}

We studied the variation in the simulated reflectances of $S$. densiflorus when $C_{a+b}$ and LAI are changed and the other variables are kept constant. At first order we will assume that the VIS-NIR reflectances depend on LAI and $C_{a+b}$.

The results of the PROSAIL sensitivity analysis of $C_{a+b}$ and LAI parameteres are shown in Fig. 5. As expected from the literature, it can be observed that, when reflectances for different values of $C_{a+b}$ and fixed LAI are plotted, an observable variation occurs between $600 \mathrm{~nm}$ and 700nm (Fig. 5A). When reflectances for different LAI values and fixed $C_{a+b}$ are plotted, the variations occurs in a wider region (between $600 \mathrm{~nm}$ and 700nm and between $800 \mathrm{~nm}$ and 1300nm) (Fig. 5B). The ranges of $C_{a+b}$ and LAI were defined as $0.73-5.75 \mu \mathrm{g} / \mathrm{cm}^{2}$ and $0.24-3.21 \mathrm{~m}^{2} / \mathrm{m}^{2}$, respectively, since the ranges could cover measured values.
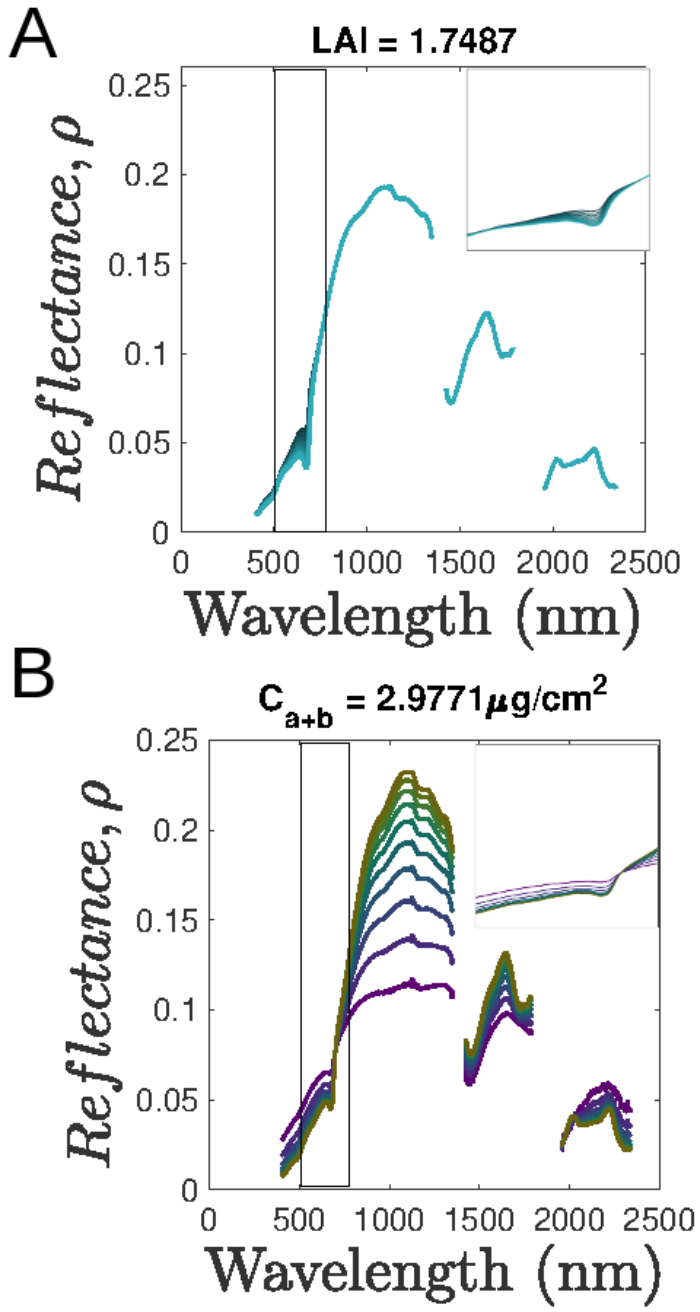

Figure 5. Sensitivity analysis. Variation in the simulated reflectances when $C_{a+b}$ (A) and LAI (B) are varied. Inset shows the reflectances between $500 \mathrm{~nm}$ and $750 \mathrm{~nm}$.

Given that the variation of $C_{a+b}$ and LAI are not independent, to retrieve $C_{a+b}$ it is necessary to find an indicator sensitive to the $C_{a+b}$ but independent of the variation of LAI. To this end, for a measured spectral signature, first of all, the LAI value can be determined from the region of Fig. 5B where the signature only depends on LAI. Then, for that LAI value, it is possible to estimate $C_{a+b}$ from the region of Fig. 5A that varies with $C_{a+b}$.

\subsection{Chlorophyll a+b content estimation}

Given a measured signature, the BLRs are computed and the LAI value in that observation can be retrieved from the $\mathrm{BLR}_{2}$ as a function of LAI curve. Then, given that LAI value, $C_{a+b}$ in the plant can be estimated from BLR 1 as a function of $C_{a+b}$.

As a result in Fig. 6 it can be observed that if $C_{a+b}$ is estimated for a real signature where all the parameters can vary with respect to the parameters fixed in the BLR modeled grid, the relation between $C_{a+b}$ estimated as a function of the measured value RMSE is $1.53 \mu \mathrm{g} / \mathrm{cm}^{2}$. As the chlorophyll content, $C_{a+b}$, varies between 0.7 and $4.7 \mu \mathrm{g} / \mathrm{cm}^{2}$ and the error is in the order of $40 \%$, this method can, therefore, distinguish between two $C_{a+b}$ conditions: a low $C_{a+b}$ (less than 1.5 $\mu \mathrm{g} / \mathrm{cm}^{2}$ ) with RMSE $=0.14 \mu \mathrm{g} / \mathrm{cm}^{2}$ or a normal value (greater than $1.5 \mu \mathrm{g} / \mathrm{cm}^{2}$ ) with RMSE $=1.72 \mu \mathrm{g} / \mathrm{cm}^{2}$. 


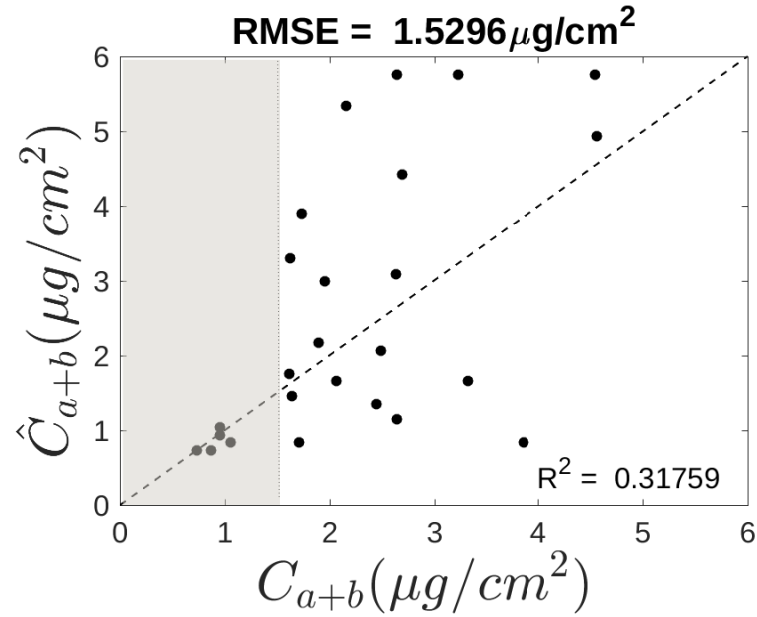

Figure 6. Estimated chlorophyll content, $\hat{C}_{a+b}$, with the BLR method as a function of the chlorophyll content, $C_{a+b}$, in a real signature. The shaded area indicates the points that correspond to $C_{a+b}$ values less than $1.5 \mu \mathrm{g} / \mathrm{cm}^{2}$.

\section{CONCLUSIONS}

In the context of the HYPERNETS project which objective is to ensure that high quality in situ measurements are available at all spectral bands and for a wide range of water and land types for the validation of the surface reflectance data issued from all earth observation mission, it is necessary to further explore its potential in different applications.

In this work the feasability to monitor a marsh site in the Mar Chiquita coastal lagoon (Argentina) was studied. Radiometric measurements at high resolution were used to characterize the range of parameters of the PROSAIL model that best fit the measured reflectances of $S$. densiflorus. The parameter distributions obtained from the simulated reflectances in Fig. 4 are consistent with the range of expected values and present in the bibliography.

A two-step algorithm based on close band triplets was proposed to retrieve $C_{a+b}$. This approach can reduce the signature to two BLRs defined by two triplet bands, and is a good method to reduce the atmospheric noise. We used simulated signatures that fit the in situ reflectances ofSporobolus densiflorus as a real field spectra acquired over $S$. densiflorus in Mar Chiquita, Argentina to test the chlorophyl content estimation methodology, which can distinguish two levels of chlorpphyl content: a low $C_{a+b}$ (less than $1.5 \mu \mathrm{g} / \mathrm{cm}^{2}$ ) or a normal value (greater than $\left.1.5 \mu \mathrm{g} / \mathrm{cm}^{2}\right)$.

\section{ACKNOWLEDGEMENTS}

This project has received funding from the European Union's Horizon 2020 research and innovation programme under grant agreement No 775983.

\section{REFERENCES}

Bedford, B. L., Preston, E. M., 1988. Developing the scientific basis for assessing cumulative effects of wetland loss and degradation on landscape functions: Status, perspectives, and prospects. Environmental Management, 12(5), 751-771.
Bortolus, A., 2006. The austral cordgrass Spartina densiflora Brong.: its taxonomy, biogeography and natural history. Journal of Biogeography, 33(1), 158-168.

Castillo, J., Fernández-Baco, L., Castellanos, E., Luque, C., Figueroa, M., Davy, A., 2000. Lower limits of Spartina densiflora and S. maritima in a Mediterranean salt marsh determined by different ecophysiological tolerances. Journal of Ecology, $88(5), 801-812$.

Clevers, J. G. P. W., Kooistra, L., 2012. Using Hyperspectral Remote Sensing Data for Retrieving Canopy Chlorophyll and Nitrogen Content. IEEE Journal of Selected Topics in Applied Earth Observations and Remote Sensing, 5(2), 574-583.

Gitelson, A., Merzlyak, M. N., 1994a. Quantitative estimation of chlorophyll-a using reflectance spectra: Experiments with autumn cnut and maple leaves. Journal of Photochemistry and Photobiology B: Biology, 22(3), 247 - 252.

Gitelson, A., Merzlyak, M. N., 1994b. Spectral Reflectance Changes Associated with Autumn Senescence of Aesculus hippocastanum L. and Acer platanoides L. Leaves. Spectral Features and Relation to Chlorophyll Estimation. Journal of Plant Physiology, 143(3), 286 - 292.

González Trilla, G., De Marco, S., Marcovecchio, J., Vicari, R., Kandus, P., 2010. Net Primary Productivity of Spartina densiflora Brong in an SW Atlantic Coastal Salt Marsh. Estuaries and Coasts, 33(4), 953-962.

González Trilla, G., Pratolongo, P., Beget, M., Kandus, P., Marcovecchio, J., Di Bella, C., 2013. Relating Biophysical Parameters of Coastal Marshes to Hyperspectral Reflectance Data in the Bahia Blanca Estuary, Argentina. Journal of Coastal Research, 231-238.

Gossn, J. I., Ruddick, K. G., Dogliotti, A. I., 2019. Atmospheric Correction of OLCI Imagery over Extremely Turbid Waters Based on the Red, NIR and $1016 \mathrm{~nm}$ Bands and a New Baseline Residual Technique. Remote Sensing, 11(3).

Hestir, E. L., Khanna, S., Andrew, M. E., Santos, M. J., Viers, J. H., Greenberg, J. A., Rajapakse, S. S., Ustin, S. L., 2008. Identification of invasive vegetation using hyperspectral remote sensing in the California Delta ecosystem. Remote Sensing of Environment, 112(11), 4034 - 4047. Applications of Remote Sensing to Monitoring Freshwater and Estuarine Systems.

Jacquemoud, S., Baret, F., 1990. PROSPECT: A model of leaf optical properties spectra. Remote Sensing of Environment, 34(2), 75 - 91.

Jacquemoud, S., Verhoef, W., Baret, F., Bacour, C., ZarcoTejada, P. J., Asner, G. P., François, C., Ustin, S. L., 2009. PROSPECT+SAIL models: A review of use for vegetation characterization. Remote Sensing of Environment, 113, S56 - S66. Imaging Spectroscopy Special Issue.

Lichtenthaler, H. K., Buschmann, C., 2001. Chlorophylls and Carotenoids: Measurement and Characterization by UV-VIS Spectroscopy. Current Protocols in Food Analytical Chemistry, 1(1), F4.3.1-F4.3.8.

Marcovecchio, J., Freije, H., De Marco, S., Gavio, A., Ferrer, L., Andrade, S., Beltrame, O., Asteasuain, R., 2006. Seasonality of hydrographic variables in a coastal lagoon: Mar Chiquita, Argentina. Aquatic Conservation: Marine and Freshwater Ecosystems, 16(4), 335-347. 
Mateos-Naranjo, E., Redondo-Gómez, S., Cox, L., Cornejo, J., Figueroa, M., 2009. Effectiveness of glyphosate and imazamox on the control of the invasive cordgrass Spartina densiflora. Ecotoxicology and Environmental Safety, 72(6), 1694 - 1700.

Nieva, F., Diaz-Espejo, A., Castellanos, E., Figueroa, M., 2001. Field Variability of Invading Populations of Spartina densiflora Brong. in Different Habitats of the Odiel Marshes (SW Spain). Estuarine, Coastal and Shelf Science, 52(4), 515 - 527.

Quan, X., He, B., Yebra, M., Yin, C., Liao, Z., Zhang, X., Li, X., 2017. A radiative transfer model-based method for the estimation of grassland aboveground biomass. International Journal of Applied Earth Observation and Geoinformation, 54, 159 - 168.

Schmidt, K., Skidmore, A., 2003. Spectral discrimination of vegetation types in a coastal wetland. Remote Sensing of Environment, 85(1), 92 - 108.

Si, Y., Schlerf, M., Zurita-Milla, R., Skidmore, A., Wang, T., 2012. Mapping spatio-temporal variation of grassland quantity and quality using MERIS data and the PROSAIL model. Remote Sensing of Environment, 121, 415 - 425.

Sims, D. A., Gamon, J. A., 2002. Relationships between leaf pigment content and spectral reflectance across a wide range of species, leaf structures and developmental stages. Remote Sensing of Environment, 81(2), 337 - 354.

Trilla, G. G., Borro, M. M., Morandeira, N. S., Schivo, F., Kandus, P., Marcovecchio, J., 2013. Allometric Scaling of Dry Weight and Leaf Area for Spartina densiflora and Spartina alterniflora in Two Southwest Atlantic Saltmarshes. Journal of Coastal Research, 1373-1381.

Vaiphasa, C., Skidmore, A. K., de Boer, W. F., Vaiphasa, T., 2007. A hyperspectral band selector for plant species discrimination. ISPRS Journal of Photogrammetry and Remote Sensing, 62(3), 225 - 235.

Verhoef, W., 1985. Earth observation modeling based on layer scattering matrices. Remote Sensing of Environment, 17(2), 165 $-178$.

Vicari, R. L., Fischer, S., Madanes, N., Bonaventura, S. M., Pancotto, V., 2002. Tiller population dynamics and production on Spartina densiflora (Brong) on the floodplain of the Parana River, Argentina. Wetlands, 22(2), 347-354.

Zarco-Tejada, P., Hornero, A., Beck, P., Kattenborn, T., Kempeneers, P., Hernández-Clemente, R., 2019. Chlorophyll content estimation in an open-canopy conifer forest with Sentinel$2 \mathrm{~A}$ and hyperspectral imagery in the context of forest decline. Remote Sensing of Environment, 223, 320 - 335. 